\title{
Sustained Remission with Mogamulizumab in Peripheral T Cell Lymphoma with Aberrant CD20 Expression: Case Report and Literature Review
}

\author{
Kentaro Fukushima', Hiroshi Sata ${ }^{1}$, Masami Imakita ${ }^{2}$, Takahiro Karasuno ${ }^{1}$ \\ ${ }^{1}$ Department of Hematology, Rinku General Medical Center, Izumisano, Osaka, Japan \\ ${ }^{2}$ Department of Pathology, Rinku General Medical Center, Izumisano, Osaka, Japan \\ Email:kfukushi@bldon.med.osaka-u.ac.jp
}

How to cite this paper: Fukushima, K., Sata, H., Imakita, M. and Karasuno, T. (2018) Sustained Remission with Mogamulizumab in Peripheral $\mathrm{T}$ Cell Lymphoma with Aberrant CD20 Expression: Case Report and Literature Review. Journal of Cancer Therapy, 9, 179-187.

https://doi.org/10.4236/jct.2018.93018

Received: September 10, 2017

Accepted: March 3, 2018

Published: March 6, 2018

Copyright $\odot 2018$ by authors and Scientific Research Publishing Inc. This work is licensed under the Creative Commons Attribution-NonCommercial International License (CC BY-NC 4.0). http://creativecommons.org/licenses/by-nc/4.0/ (c) (i) (8) Open Access

\begin{abstract}
A 82-year-old man presented with an enlarged multiple superficial lymph nodes. The histological diagnosis of lymph node was peripheral $\mathrm{T}$ cell lymphoma, not otherwise specified (PTCL-NOS), with an aberrant expression of CD20. Generally, PTCL lacks B cell antigen such as CD19 or CD20, however, rare cases have been reported in the literature that showed PTCL patients expressing the $\mathrm{B}$ cell antigens. It is considered that the prognosis of $\mathrm{CD} 20$ positive PTCL is poor, however, standard therapy has not been established. He was treated with eight cycles of $\mathrm{CHOP}$ regimen, but the enlargement of a part of lymph nodes still remained. Recently, it is reported that C-C Chemokine receptor type 4 (CCR4) is known to be expressed about $50 \%$ case of PTCL and CCR4 target therapy is effective. Our case was positive for CCR4 so mogamulizumab (anti-CCR4 antibody) was administered. Consequently, dramatic response was obtained and its combination of these therapy resulted in complete remission for 24 months. This is the first case of sustained remission by administration of mogamulizumab against CCR4/CD20 double positive PTCL. This strategy may be benefit to obtain the good prognosis.
\end{abstract}

\section{Keywords}

Peripheral T Cell Lymphoma, CD20, PTCL-NOS, Aberrant Expression, Mogamulizumab

\section{Introduction}

Generally, PTCL is known to be a kind of T cell malignancy and lacks B cell antigen, however, rare cases have been reported in the literature that showed PTCL 
patients expressing the B cell antigens. It is considered that the prognosis of CD20 positive PTCL is poor, however, standard therapy has not been established. Recently, it is reported that CCR4 target therapy is effective for CCR4 positive PTCL. Here we present the first case of a successful combination chemotherapy followed by mogamulizumab treatment in peripheral $\mathrm{T}$ cell lymphoma with aberrant CD20 expression.

\section{Patients}

The 82-year-old man had appetite loss and general fatigue because of highly dehydration for two weeks and referred to our hospital. Physical examination revealed bilateral neck, axial and inguinal lymph nodes swelling and severe dry skin. The laboratory findings were as follows: white blood cell count of $2620 / \mu \mathrm{L}$ with $22.4 \%$ neutrophils, a red blood cell count of $395 \times 10^{4} / \mu \mathrm{L}$, and a platelet count of $13.8 \times 10^{4} / \mu \mathrm{L}$. The level of lactate dehydrogenase (LDH) was elevated at $242 \mathrm{U} / \mathrm{L}$ despite normal levels of alanine aminotransferase and aspartate transaminase. Serum level of soluble interleukin 2 receptor was also elevated at 1060 U/L. Serum human immunodeficiency virus was negative. Chest X-ray showed blunting of the right costophrenic angle. Computed tomography (CT) scan of the whole body revealed enlarged lymph nodes in bilateral cervical, subclavicular, axial, mediastinal, abdominal-paraaortic and inguinal areas. Fluorodeoxyglucose-positron emission tomography (FDG/PET) scan revealed abnormal uptake in paratracheal lymph node with a maximum standardized uptake value (SUVmax) of 9.1, abdominal para-aortic lymph node with SUVmax of 8.9 and inguinal lymph node with SUVmax of 4.0. Inguinal lymph node biopsy was performed and it showed the highly monomorphous cytological spectrum and small-sized lymphocytes were infiltrated with diffuse feature (Figure 1(a)). Immunohistochemically, the tumor cells were positive for CD20 (L26), CD3, CD45RO (UCHL-1), TIA-1, CCR4, and Granzyme B, while were negative for CD4, CD8, CD5, CD56, CD79a, TdT, bcl-2, bcl-6, CD10, CD23, CD1a, and cyclin D1 (Figure 1(b)). Ki-67 labeling index was 19.4\% (Figure 1(d)). Flow cytometric analysis showed $69.5 \%$ of $\mathrm{CD} 3$ positive cells were also positive for CD20 (Figure 1(c)). Southern blot analysis demonstrated T-cell receptor $\mathrm{C}$ beta-chain gene rearrangement but no rearrangement of immunoglobulin heavy chain (Figure 2). Karyotype of lymph node showed a complex chromosomal abnormality: 46, XY, t $(1 ; 11)$ (p34; q23). Bone marrow biopsy showed the involvement of small-sized lymphocytes with co-expression of CD20 and CD3. These findings led to a diagnosis of peripheral T-cell lymphoma, not otherwise specified (PTCL-NOS) with an aberrant expression of CD20. CHOP (Cyclophosphamide, doxorubicin, vincristine and prednisolone) was started. CT scan showed after 6 courses of CHOP, almost lymph nodes had been reduced but the enlargement of mediastinal lymph node and abdominal lymph nodes was still remained. Bone marrow examination revealed no infiltration of lymphoma cells. Our patient received an additional 2 courses of CHOP, but CT scan did not show the 


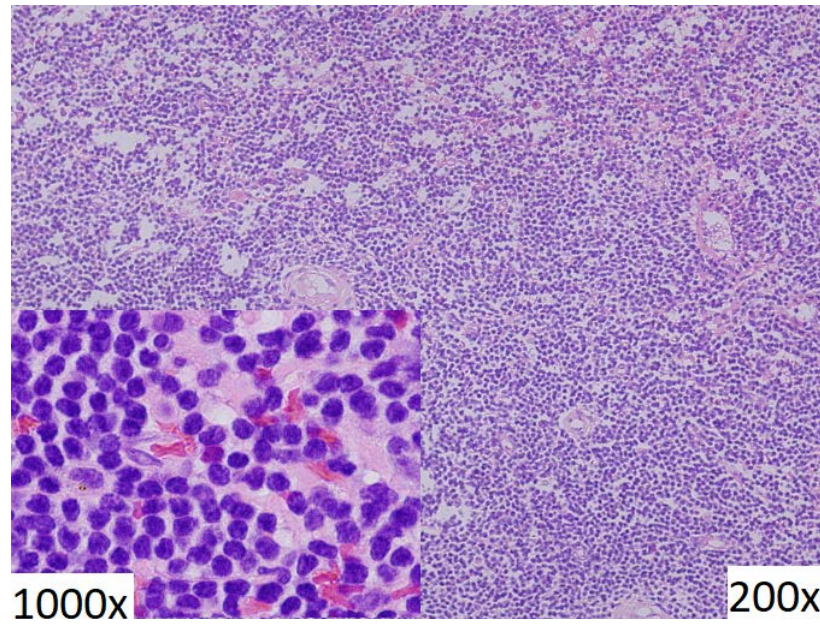

(a)

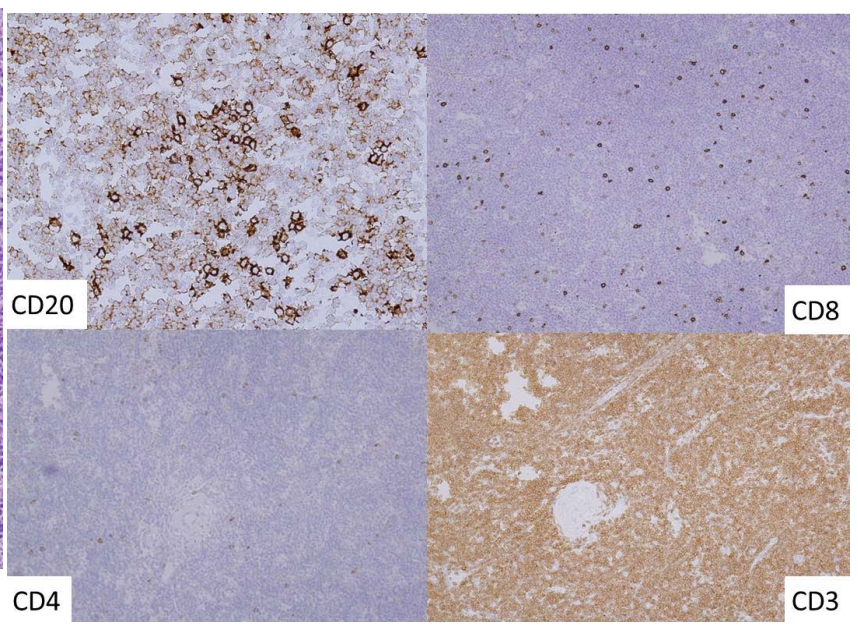

(b)
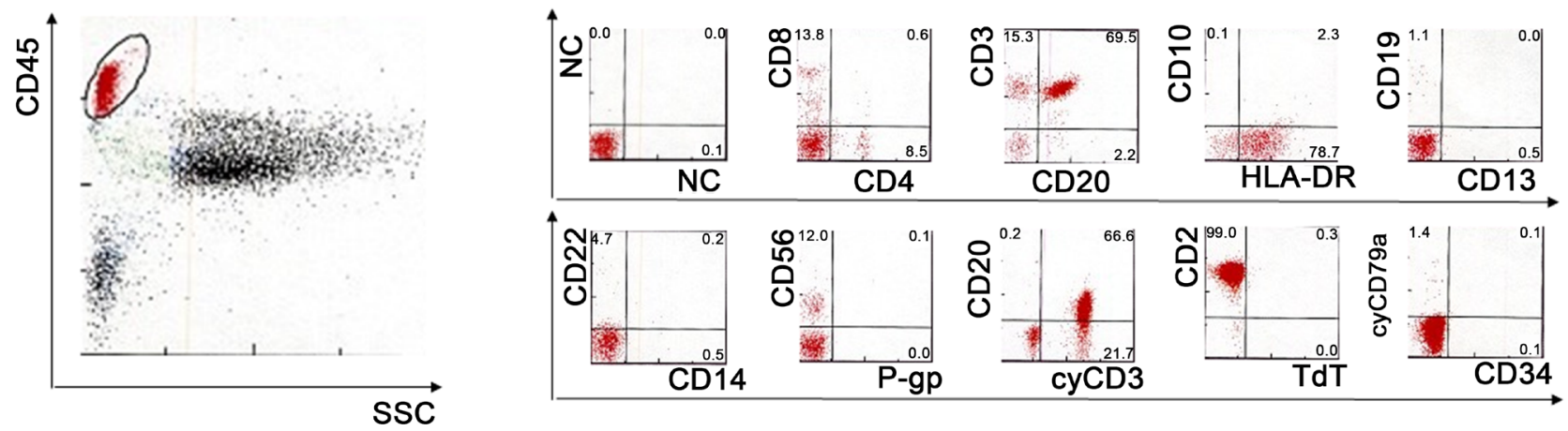

(c)

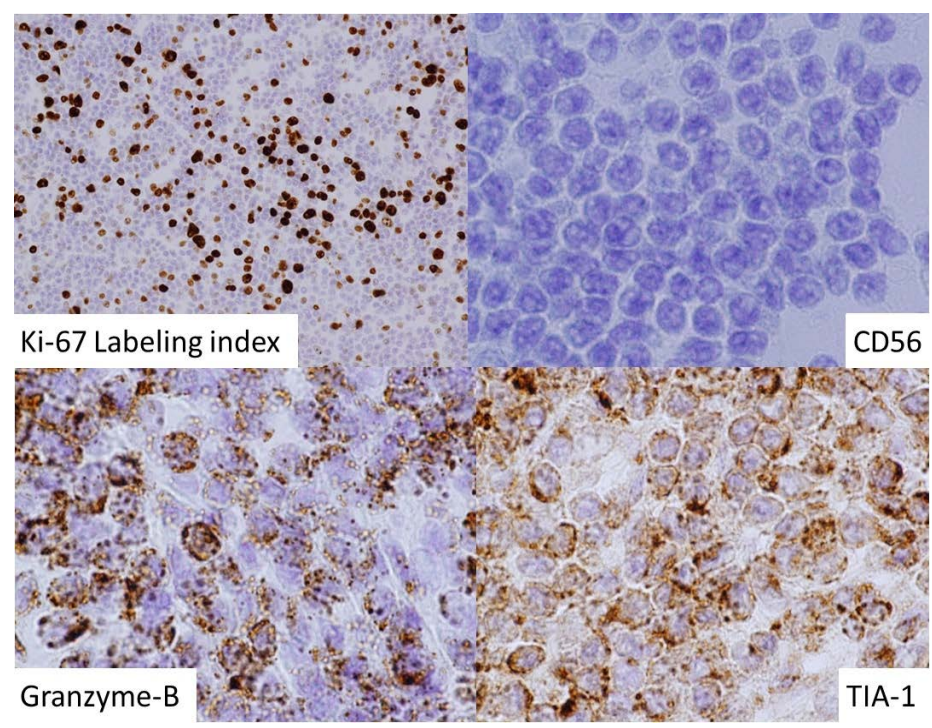

(d)

Figure 1. (a) Pathological findings of a biopsied specimen. Small round tumor cells infiltrates with diffuse features; (b) Immunohistochemical findings of a biopsied specimen. The majority of the lymphoma cells are positive for CD20, CD3 and negative for CD4, CD8; (c) Flow cytometric analyses of lymph node cells. All cells were stained by CD45 and identified hematopoietic cells or non-hematopoietic cells. CD20 and CD3 double positive cells are observed in 69.5\% of gated cells; (d) Examination of cytotoxic molecules expression using immunohistochemical staining. Immunohistochemical findings. Ki-67 labeling index is $19.4 \%$. Cytotoxic granules such as granzyme-B and TIA-1 are expressed on almost all of lymphoma cells but not CD56. 


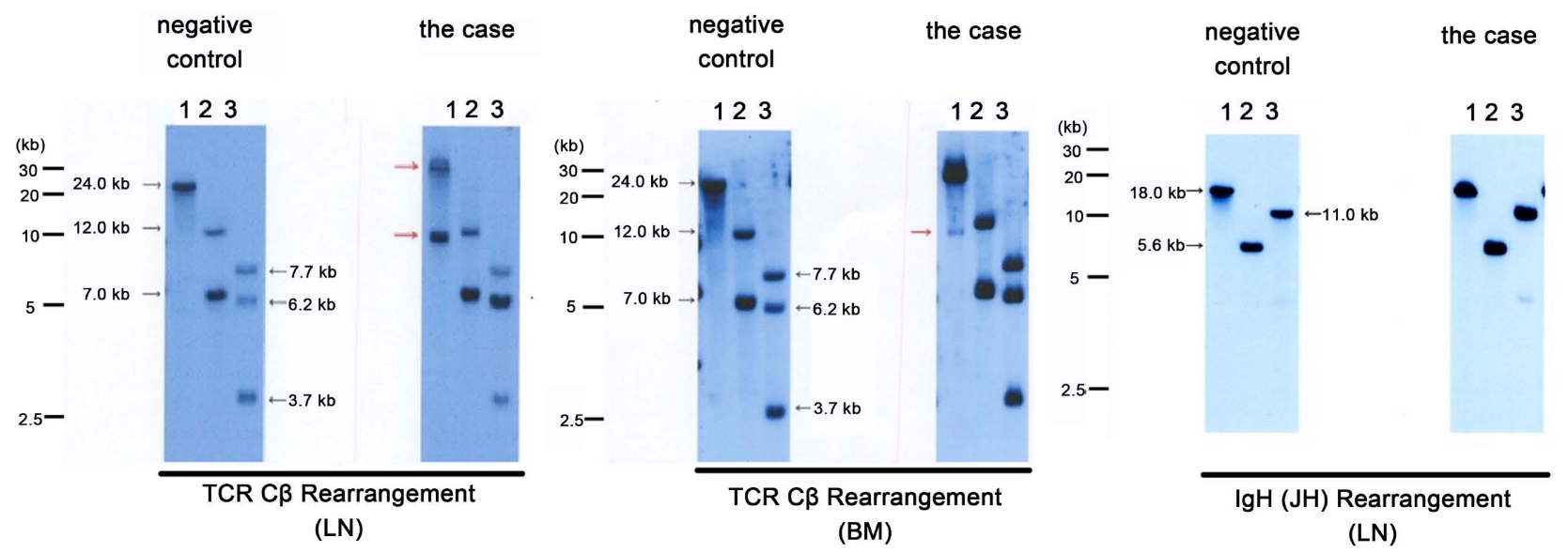

Figure 2. Southern blot analysis for T/B cell rearrangement on the biopsy specimen from the lymph node. Total genomic DNA was digested with BamHI: 1st lane; EcoRV: 2nd lane; HindIII: 3rd lane. The rearrangement bands of TCR C $\beta 1$ were detected in lane 1 of the present case (b) compared with the negative control. The rearrangement bands of $\operatorname{Ig}(\mathrm{H}) \mathrm{JH}$ were not detected in any lane of the present case compared with the negative control.

disappearance of residual regions. Therefore, we decided the use of mogamulizumab for the second therapy. Mogamulizumab was administered at the dose of $1 \mathrm{mg} / \mathrm{kg}$ every two weeks. After 8 courses of mogamulizumab monotherapy, FDG/PET scan revealed the resolution of FDG uptake (Figure 3). Two years has passed since the administration of mogamulizumab therapy and the patient remains in remission.

\section{Discussion}

PTCL is a kind of T cell malignancy which is generally originated from mature helper T cell/killer T cell and lack B cell lineage [1]. PTCLs are considered highly aggressive lymphoma and overall survival and progression free survival are lower $(20 \% \sim 30 \%)$ than other lymphomas. With respect to prognostic factors for PTCL, PIT: prognostic index for PTCL-unspecified (PTCL-U) was proposed by Gallamini et al. and was frequently used [2]. The factors of this index include age, performance status, serum LDH level and bone marrow involvement. According to the PIT index, our case revealed group 4 that was estimated about $20 \%$ overall survival for 2 years. Phenotypically, PTCL-NOS is usually characterized by T-cell phenotype with frequent down regulation of CD5 and CD7 [1]. $\mathrm{CD} 4 / 8$ double negativity is occasionally seen [3]. Cytotoxic granule such as TIA-1 ( $\mathrm{T}$ cell intracellular antigen-1) and granzyme B are exocytosed during specific interaction with target cells and CD8 positive cytotoxic $\mathrm{T}$ cells [4]. These granules are detected in anaplastic large cell lymphoma and extranodal NK/T-cell lymphoma, rarely detected in PTCL-NOS or adult $\mathrm{T}$ cell leukemia/lymphoma (ATLL). Asano et al. reported that complete remission rate was $30 \%$ for the cytotoxic molecule, TIA-1 and granzyme B positive PTCL, while it is $63 \%$ for the negative. As a result, cytotoxic molecule expression in PTCL-U is considered to be a significant prognostic factor, independent from other clinical factors or prognostic index scores. These criteria also suggested that our patient 


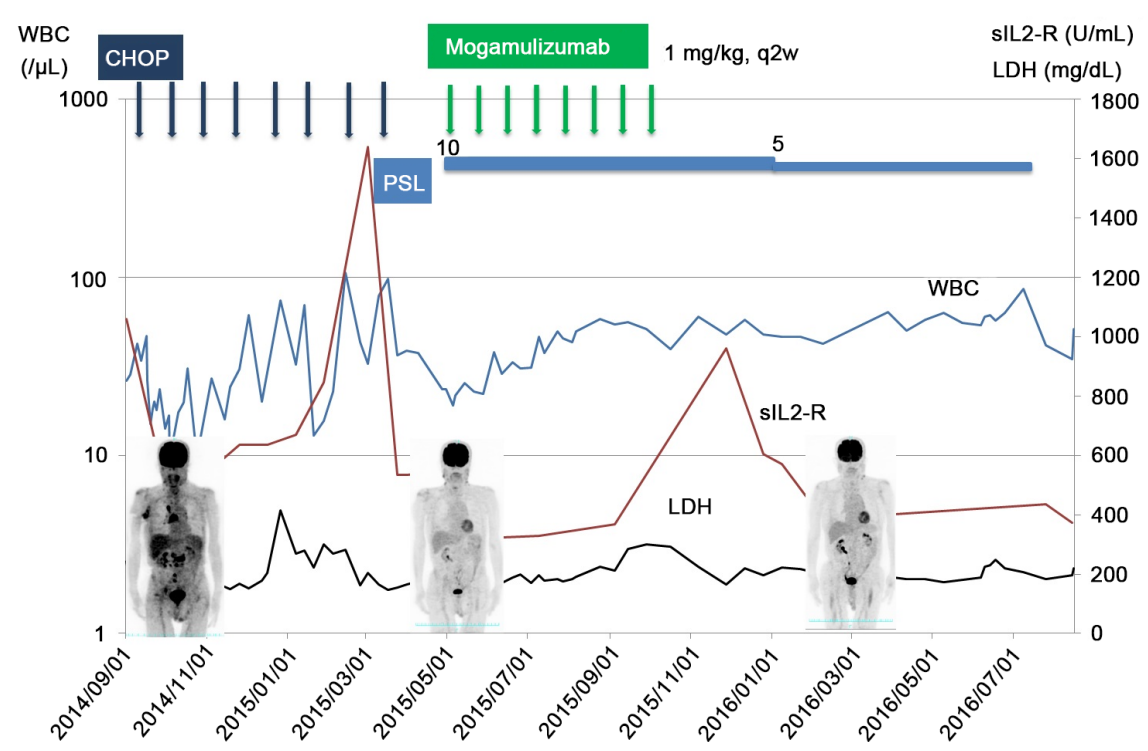

Figure 3. Clinical course. 8-cycles CHOP were performed. During chemotherapy, soluble IL2-R value was gradually declined without febrile neutropenia at course 7 . After chemotherapy, residual lesions were detected by FDG-PET-CT compared to initial evaluation. Then 8-courses of mogamulizumab were administered once bi-weekly. After mogamulizumab monotherapy, PET-CT revealed in complete remission. Each line shows that Blue line: White blood cell count (WBC); Red line: soluble interleukin 2-receptor (sIL2-R); Black line: lactate dehydrogenase (LDH).

had worse prognosis. Conventional chemotherapy such as CHOP or CHOP like regimen has remained as standard therapy for PTCL since 1970s, but it has not led to an adequate prolongation of prognosis [5] [6]. D'amore et al. reported the favorable outcome of the intensive chemotherapy followed by up-front autologous stem cell transplantation (ASCT) in PTCL as a large prospective phase II study [7]. On the other hand, Yam et al. indicated that ASCT did not appear to improve progression free survival [8]. Thus, no standard therapy for PTCLs has been established. It is reported that CD20 positive PTCL is a group of diseases with a very poor prognosis of about 7 months in total survival. Toya et al. showed that the overall survival rate of CHOP therapy for PTCL was $69.6 \%$ in CD20 negative PTCL, whereas it was only $33.3 \%$ in CD20 positive PTCL and the remission rate was also low in CD20 positive PTCL [9]. Although several cases using conventional chemotherapy or radiotherapy have been reported, favorable results have not been archived [10] [11] [12]. The significance of CD20 expression in PTCL were remained unclear, although it is speculated CD20 positive lymphoma arises from immature common lymphoid progenitors, which are able to differentiate not only B but also T cells [13]-[18]. During these past 20 years, administration of rituximab (anti-CD20 antibody) is recognized as a standard therapy in CD20 positive B cell malignancy. On the other hand, target therapy against CD20 seemed to be a novel therapy for CD20 positive PTCL compared with conventional chemotherapy. Then we summarized previous reports administrating rituximab for CD20 positive PTCL in Table 1.6 cases were in relapse or dead within 12 months and 
Table 1. Review of cases treated with MoAb for CD20-positive PTCL. Only 25\% of previously reported 8 cases treated with Rituximab archived remission. Our case archived complete remission for 24 months. a) TCR: rearrangement of T cell receptor; b) IgH: rearrangement of B cell receptor (JH); c) CTx: Chemotherapy; d) MoAb: Monoclonal antibody.

\begin{tabular}{|c|c|c|c|c|c|c|c|c|c|c|c|c|}
\hline Case & Reference & Age & Race & Disease & $\mathrm{CD} 20$ & $\mathrm{CD} 4$ & CD8 & $\mathrm{TCR}^{\mathrm{a}}$ & $\operatorname{IgH}^{\mathrm{b}}$ & $\mathrm{CTx}^{\mathrm{c}}$ & $M_{o} A b^{d}$ & Outcome \\
\hline 1 & Rahemtullah et al. & $77 \mathrm{M}$ & Caucasians & PTCL-U & $\operatorname{dim}$ & + & - & + & - & Y & Rituximab & $\begin{array}{c}\text { Undergoing } \\
\text { treatment } \\
(4 \mathrm{M})\end{array}$ \\
\hline 2 & Rahemtullah et al. & $36 \mathrm{~F}$ & Caucasians & PTCL-U & $\operatorname{dim}$ & + & - & + & - & Y & Rituximab & $\begin{array}{l}\text { CR } \rightarrow \text { Relapse } \\
\rightarrow \text { Dead }(16 \mathrm{M})\end{array}$ \\
\hline 3 & Rahemtullah et al. & $75 \mathrm{M}$ & Caucasians & PTCL-U & + & - & - & + & - & Y & Rituximab & Relapse(10M) \\
\hline 4 & Magro et al. & $65 \mathrm{~F}$ & Caucasians & Cutaneous PTCL & + & NR & + & + & + & Y & Rituximab & Relapse(2Y) \\
\hline 5 & Buckner et al. & $84 \mathrm{M}$ & Caucasians & PTCL-U & $\operatorname{dim}$ & + & NR & + & NR & Y & Rituximab & Dead(6M) \\
\hline 6 & Cumiskey et al. & $84 \mathrm{M}$ & Caucasians & PTCL-U & + & + & NR & + & - & Y & Rituximab & CR \\
\hline 7 & Makita et al. & $59 \mathrm{M}$ & Orientals & PTCL-NOS & + & - & - & + & - & Y & Rituximab & $\begin{array}{c}\text { PR } \rightarrow \text { Relapse } \\
\rightarrow \text { Dead }(16 \mathrm{M})\end{array}$ \\
\hline 8 & Hirata et al. & $74 \mathrm{M}$ & Orientals & PTCL-NOS & + & + & - & + & - & Y & Rituximab & $\begin{array}{l}\text { CR } \rightarrow \text { Relapse } \\
\rightarrow \text { Dead (1Y) }\end{array}$ \\
\hline 9 & This case & $82 \mathrm{M}$ & Orientals & PTCL-NOS & + & - & - & + & - & $\mathrm{Y}$ & Mogamulizumab & $\mathrm{CR}(24 \mathrm{M})$ \\
\hline
\end{tabular}

the treatment efficacy of rituximab administration seemed to be limited [10] [19] [20] [21]. It is known that expression of CD20 in flow cytometry is weaker in PTCL than in B cell tumor. The expression intensity of CD20 may be associated with the effectiveness of rituximab [2] [10] [19].

Recently, CCR4 protein is reported as a chemokine receptor having two ligands: CCL17 which is also known as TARC (Thymus and activation regulated chemokine) and CCL22 known as macrophage-derived chemokine, and is found $>90 \%$ of cases with adult T-cell lymphoma/leukemia (ATLL) and in $20 \%$ $\sim 30 \%$ of cases with PTCL [22]. Moreover, mogamulizumab, which is a defucosylated humanized anti-CCR4 antibody, demonstrated potential efficacy and tolerability in patients with relapsed CCR4-positive PTCL and ATLL [23]. Common adverse events of mogamulizumab are neutropenia, thrombocytopenia and acute infusion reaction such as fever and rush. However, these adverse events were tolerable under the appropriate treatment such as corticosteroid. Thus, mogamulizumab would be also considerable for elderly patients and promising target therapy for CCR4-positive PTCL and ATLL.

Herein, we present the first case of a successful combination chemotherapy followed by mogamulizumab treatment. Thus, it is important that the expression of CCR4 chemokine is examined and then optimal treatment procedure for CD20 positive PTCL may be determined. Further investigation would be necessary for establishing strategy for CD20 and CCR4 double positive PTCL.

\section{Conflict of Interest}

The authors state that they have no Conflict of Interest (COI). 


\section{References}

[1] Armitage, J.O. (2012) The Aggressive Peripheral T-Cell Lymphomas: 2012 Update on Diagnosis, Risk Stratification, and Management. American Journal of Hematology, 87, 511-519.

[2] Gallamini, A., Stelitano, C., Calvi, R., Bellei, M., Mattei, D., Vitolo, U., Morabito, F., Martelli, M., Brusamolino, E., Iannitto, E., Zaja, F., Cortelazzo, S., Rigacci, L., Devizzi, L., Todeschini, G., Santini, G., Brugiatelli, M., Federico, M. and Linfomi, I.I. (2004) Peripheral T-Cell Lymphoma Unspecified (PTCL-U): A New Prognostic Model from a Retrospective Multicentric Clinical Study. Blood, 103, 2474-2479. https://doi.org/10.1182/blood-2003-09-3080

[3] Ichikawa, S., Hatta, S., Saito, Y., Kimura, J., Onishi, K., Matsuda, M., Ichinohasama, R. and Harigae, H. (2012) CD20-Positive and CD4/CD8-Double-Negative Peripheral T-Cell Lymphoma of Spleen Complicated with Severe Disseminated Intravascular Coagulation and Enteropathy. Journal of Clinical and Experimental Hematopathology, 52, 133-136.

[4] Asano, N., Suzuki, R., Matsuo, K., Kagami, Y., Ishida, F., Tamaru, J.I., Jin, G.S., Sato, Y., Shimoyama, Y., Yoshino, T., Morishima, Y. and Nakamura, S. (2007) Cytotoxic Molecule Expression Is Predictive of Prognosis in Hodgkin's-Like Anaplastic Large Cell Lymphoma. Histopathology, 50, 705-715.

[5] Takamatsu, Y., Suzumiya, J., Utsunomiya, A., Maeda, K., Matsuoka, H., Suzushima, H., Tsukada, J., Shibata, K. and Tamura, K. (2010) THP-COP Regimen for the Treatment of Peripheral T-Cell Lymphoma and Adult T-Cell Leukemia/Lymphoma: A Multicenter Phase II Study. European Journal of Haematology, 84, 391-397.

[6] Tomita, N., Kodama, F., Tsuyama, N., Sakata, S., Takeuchi, K., Ishibashi, D., Koyama, S., Ishii, Y., Yamamoto, W., Takasaki, H., Hagihara, M., Kuwabara, H., Tanaka, M., Hashimoto, C., Yamazaki, E., Koharazawa, H., Fujimaki, K., Sakai, R., Fujisawa, S. and Ishigatsubo, Y. (2015) Biweekly THP-COP Therapy for Newly Diagnosed Peripheral T-Cell Lymphoma Patients. Hematological Oncology, 33, 9-14.

[7] d'Amore, F., Relander, T., Lauritzsen, G.F., Jantunen, E., Hagberg, H., Anderson, H., Holte, H., Osterborg, A., Merup, M., Brown, P., Kuittinen, O., Erlanson, M., Ostenstad, B., Fagerli, U.M., Gadeberg, O.V., Sundstrom, C., Delabie, J., Ralfkiaer, E., Vornanen, M. and Toldbod, H.E. (2012) Up-Front Autologous Stem-Cell Transplantation in Peripheral T-Cell Lymphoma: NLG-T-01. Journal of Clinical Oncolo$g y$, 30, 3093-3099. https://doi.org/10.1200/JCO.2011.40.2719

[8] Yam, C., Landsburg, D. J., Nead, K.T., Lin, X., Mato, A.R., Svoboda, J., Loren, A. W., Frey, N.V., Stadtmauer, E.A., Porter, D.L., Schuster, S.J. and Nasta, S.D. (2016) Autologous Stem Cell Transplantation in First Complete Remission May Not Extend Progression-Free Survival in Patients with Peripheral T Cell Lymphomas. American Journal of Hematology, 91, 672-676.

[9] Toya, T., Nannya, Y., Hangaishi, A., Shiseki, M., Shimoyama, T., Sakamaki, H., Motoji, T., Usuki, K., Nakamura, F. and Kurokawa, M. (2015) Prognostic Relevance of CD20 Expression in Peripheral T-Cell Lymphomas: A Multi-Center Retrospective Study. Leukemia \& Lymphoma, 57, 961-964. https://doi.org/10.3109/10428194.2015.1083097

[10] Quintanilla-Martinez, L., Preffer, F., Rubin, D., Ferry, J.A. and Harris, N.L. (1994) CD20+ T-Cell Lymphoma. Neoplastic Transformation of a Normal T-Cell Subset. American Journal of Clinical Pathology, 102, 483-489. https://doi.org/10.1093/ajcp/102.4.483

[11] Oshima, H., Matsuzaki, Y., Takeuchi, S., Nakano, H. and Sawamura, D. (2009) 
CD20 ${ }^{+}$Primary Cutaneous T-Cell Lymphoma Presenting as a Solitary Extensive Plaque. British Journal of Dermatology, 160, 894-896.

[12] Blakolmer, K., Vesely, M., Kummer, J.A., Jurecka, W., Mannhalter, C. and Chott, A. (2000) Immunoreactivity of B-Cell Markers (CD79a, L26) in Rare Cases of Extranodal Cytotoxic Peripheral T- (NK/T-) Cell Lymphomas. Modern Pathology, 13, 766-772. https://doi.org/10.1038/modpathol.3880133

[13] Yao, X., Teruya-Feldstein, J., Raffeld, M., Sorbara, L. and Jaffe, E.S. (2001) Peripheral T-Cell Lymphoma with Aberrant Expression of CD79a and CD20: A Diagnostic Pitfall. Modern Pathology, 14, 105-110. https://doi.org/10.1038/modpathol.3880265

[14] Balmer, N.N., Hughey, L., Busam, K.J., Reddy, V. and Andea, A.A. (2009) Primary Cutaneous Peripheral T-Cell Lymphoma with Aberrant Coexpression of CD20: Case Report and Review of the Literature. The American Journal of Dermatopathology, 31, 187-192. https://doi.org/10.1097/DAD.0b013e31818cc039

[15] Buckner, C.L., Christiansen, L.R., Bourgeois, D., Lazarchick, J.J. and Lazarchick, J. (2007) CD20 Positive T-Cell Lymphoma/Leukemia: A Rare Entity with Potential Diagnostic Pitfalls. Annals of Clinical \& Laboratory Science, 37, 263-267.

[16] Magro, C.M., Seilstad, K.H., Porcu, P. and Morrison, C.D. (2006) Primary $\mathrm{CD} 20^{+} \mathrm{CD} 10^{+} \mathrm{CD}^{+} \mathrm{T}$-Cell Lymphoma of the Skin with IgH and TCR $\beta$ Gene Rearrangement. American Journal of Clinical Pathology, 126, 14-22. https://doi.org/10.1309/HPYGFLNXKFBHDQEV

[17] Went, P., Agostinelli, C., Gallamini, A., Piccaluga, P.P., Ascani, S., Sabattini, E., Bacci, F., Falini, B., Motta, T., Paulli, M., Artusi, T., Piccioli, M., Zinzani, P.L. and Pileri, S.A. (2006) Marker Expression in Peripheral T-Cell Lymphoma: A Proposed Clinical-Pathologic Prognostic Score. Journal of Clinical Oncology, 24, 2472-2479. https://doi.org/10.1200/JCO.2005.03.6327

[18] Mohrmann, R.L. and Arber, D.A. (2000) CD20-Positive Peripheral T-Cell Lymphoma: Report of a Case after Nodular Sclerosis Hodgkin's Disease and Review of the Literature. Modern Pathology, 13, 1244-1252. https://doi.org/10.1038/modpathol.3880229

[19] Arai, H., Maki, K., Tadokoro, J., Handa, T., Nakamura, Y., Tsurumi, S., Sasaki, K. and Mitani, K. (2012) CD20-Positive Peripheral T-Cell Lymphoma, Not Otherwise Specified. Rinsho Ketsueki, 53, 705-709. (In Japanese)

[20] Makita, M., Murakami, I., Yoshioka, T., Tanaka, H., Yamamoto, K., Imajo, K., Takata, K. and Yoshino, T. (2009) Extranodal CD20-Positive Peripheral T-Cell Lymphoma Presenting with Adrenal and Testicular Masses. Rinsho Ketsueki, 50, 413-418. (In Japanese)

[21] Rahemtullah, A., Longtine, J.A., Harris, N.L., Dorn, M., Zembowicz, A., Quintanilla-Fend, L., Preffer, F.I. and Ferry, J.A. (2008) CD20 ${ }^{+}$T-Cell Lymphoma: Clinicopathologic Analysis of 9 Cases and a Review of the Literature. The American Journal of Surgical Pathology, 32, 1593-1607. https://doi.org/10.1097/PAS.0b013e31817d7452

[22] Ishida, T., Inagaki, H., Utsunomiya, A., Takatsuka, Y., Komatsu, H., Iida, S., Takeuchi, G., Eimoto, T., Nakamura, S. and Ueda, R. (2004) CXC Chemokine Receptor 3 and CC Chemokine Receptor 4 Expression in T-Cell and NK-Cell Lymphomas with Special Reference to Clinicopathological Significance for Peripheral T-Cell Lymphoma, Unspecified. Clinical Cancer Research, 10, 5494-5500. https://doi.org/10.1158/1078-0432.CCR-04-0371

[23] Ogura, M., Ishida, T., Hatake, K., Taniwaki, M., Ando, K., Tobinai, K., Fujimoto, K., Yamamoto, K., Miyamoto, T., Uike, N., Tanimoto, M., Tsukasaki, K., Ishizawa, K., 
Suzumiya, J., Inagaki, H., Tamura, K., Akinaga, S., Tomonaga, M. and Ueda, R. (2014) Multicenter Phase II Study of Mogamulizumab (KW-0761), a Defucosylated Anti-CC Chemokine Receptor 4 Antibody, in Patients with Relapsed Peripheral T-Cell Lymphoma and Cutaneous T-Cell Lymphoma. Journal of Clinical Oncology, 32, 1157-1163. https://doi.org/10.1200/JCO.2013.52.0924 